\title{
Abnormal Motor Cortex Excitability in Congenital Stroke
}

\author{
STEFFEN BERWECK, MICHAEL WALTHER, VERENA BRODBECK, NINA WAGNER, INGA KOERTE, VOLKMAR HENSCHEL, \\ HENDRIK JUENGER, MARTIN STAUDT, AND VOLKER MALL
}

\begin{abstract}
Department of Pediatric Neurology and Developmental Medicine [S.B., V.B., N.W., I.K.], Dr. von Hauners' Children's Hospital of the University of Munich, 80337 Munich, Germany; Department of Neuropediatrics and Muscle Disorders [M.W., V.M.], University

Children's Hospital, 79106 Freiburg, Germany; Institute of Med. Informatics, Biometry and Epidemiology [V.H.], University of Munich, 81377 Munich, Germany; Department of Neuropediatrics [H.J., M.S.], University Children's Hospital, 72076 Tübingen, Germany
\end{abstract}

\begin{abstract}
The aim of the present study was to investigate corticospinal and intracortical excitability in patients with congenital stroke. In adults, stroke sequelae reduce corticospinal excitability, as indicated by an elevated threshold for motor evoked potentials (MEP), and increase intracortical excitability, as indicated by reduced intracortical inhibition. Ten patients with pre- or perinatally acquired, unilateral cortico-subcortical infarctions in the middle cerebral artery territory were studied with single pulse transcranial magnetic stimulation (TMS) to measure motor threshold (MT) and with paired pulse TMS to study short interval intracortical inhibition (SICI) and intracortical facilitation (ICF). Eight healthy, age-matched subjects served as controls. MT over the affected hemisphere of patients compared with the dominant hemisphere of controls was significantly elevated, reflecting reduced corticospinal excitability, and SICI was significantly reduced, reflecting increased intracortical excitability. No such differences were found for ICF. Findings in patients with congenital stroke were comparable with adulthood stroke. Thus, similar assumptions can be made: reduced corticospinal excitability is probably a consequence of neuronal damage. Reduced intracortical inhibition might represent deficient inhibitory cortical properties or might reflect a compensational mechanism, dispositioning for use-dependent plasticity. (Pediatr Res 63: 84-88, 2008)
\end{abstract}

$\mathrm{T}_{\mathrm{p}}$ he human brain is capable of reorganization (1-3). In patients with congenital stroke, reorganization is determined by the maturational state of the brain at the time of the insult (4). Early studies using transcranial magnetic stimulation (TMS) focused on corticospinal connectivity and revealed in some patients preserved ipsilateral motor pathways from the undamaged motor cortex to the hemiplegic hand (5-9). Subsequent studies combining TMS with structural and functional magnetic resonance imaging (MRI) revealed that the type of corticospinal reorganization as well as the compensatory recruitment of areas within the contralesional hemisphere depend on the extent of the underlying brain lesion (10). Furthermore, location and timing period affect the type and efficacy of reorganization, with significant impact on clinical outcome (11).

Received May 30, 2007; accepted September 4, 2007

Correspondence: Steffen Berweck, M.D., Department of Pediatric Neurology and Developmental Medicine, Dr. von Hauner's Children's Hospital, University of Munich, Lindwurmstr. 4, 80337 Munich, Germany; e-mail: steffen.berweck@med.unimuenchen.de

This work was supported by a grant of the "Deutsche Forschungsgemeinschaft," application no. STA 859/1-1, BE 3235/1-1, MA 3306/1-1.

V.M. and M.S. contributed equally to this work.
Until now, studies investigating intracortical excitability by transcranial magnetic paired pulse stimulation have been conducted only in patients with adulthood stroke (12-15). This technique allows us to study changes in the excitability of both inhibitory and excitatory intracortical circuits, a mechanism credited to be involved in reorganization of the brain (16-19). In adulthood, cortical stroke intracortical excitability is increased, as indicated by a reduced intracortical inhibition with a heightened amplitude of the conditioned motor evoked potential (MEP) (12-15). There is evidence from developmental studies that corticospinal excitability as well as intracortical excitability are age dependent and are not fully established up to several years postnatally $(20-23)$. Given that the sensorimotor system at the time the lesion occurred was immature, results from patients with adulthood stroke on motor cortex excitability cannot be applied to patients with congenital stroke offhand (24). Therefore, we measured corticospinal and intracortical excitability in a group of patients with congenital stroke and compared the results with an age-matched group of healthy subjects. To avoid pooling of different types of plastic reorganization, we recruited a sample of patients with congenital stroke that was as homogenous as possible: only patients with unilateral, cortico-subcortical infarctions in the middle cerebral artery territory, acquired during the late third trimester of pregnancy or perinatally, and crossed corticospinal projections from the affected hemisphere to the paretic hand were included. Here, we asked whether similar changes of motor cortex excitability as observed in adulthood cortical stroke could be found.

\section{METHODS}

Informed written consent of parents and subjects older than $18 \mathrm{y}$ of age was obtained. The study was approved by the local ethics committee of Tübingen.

Ten patients ( 5 females, age range $10-30 \mathrm{y}$, median $14 \mathrm{y}$ ) were recruited from a large population of patients with unilateral spastic cerebral palsy overseen at the three participating university hospitals. Patients with a bilateral pathology, brain malformations, or periventricular lesions on structural MRI, a history of epileptic seizures, who were on any chronic medication or

\footnotetext{
Abbreviations: EMG, electromyography; FPB, flexor pollicis brevis muscle; ICF, intracortical facilitation; ISI, interstimulus interval; M1-aff, patients' affected hemisphere; M1-cl, patients' contralesional hemisphere; M1-ndom, controls' nondominant hemisphere; MEP, motor evoked potential; RMT, resting motor threshold; SICI, short interval intracortical inhibition; TMS, transcranial magnetic stimulation
} 
Table 1. Patients' and controls' characteristics and resting motor threshold (RMT)

\begin{tabular}{|c|c|c|c|c|c|c|c|c|}
\hline \multirow[b]{2}{*}{ Patients } & \multirow[b]{2}{*}{ Sex } & \multirow[b]{2}{*}{ Age } & \multirow[b]{2}{*}{ MACS } & \multirow[b]{2}{*}{ Side of paresis } & \multirow[b]{2}{*}{ Localization of lesion } & \multicolumn{3}{|c|}{$\mathrm{RMT}(\% \mathrm{SO})$} \\
\hline & & & & & & Affected & Contralesional & Ipsilateral \\
\hline 1 & $\mathrm{~F}$ & 11 & 1 & Right & $\mathrm{fp}$ & 83 & 55 & - \\
\hline 2 & $\mathrm{~F}$ & 19 & 2 & Right & $\mathrm{fpt}$ & 59 & 55 & - \\
\hline 3 & $\mathrm{~F}$ & 10 & 2 & Right & $\mathrm{fp}$ & 80 & 58 & - \\
\hline 4 & M & 20 & 1 & Left & $\mathrm{fp}$ & 82 & 40 & - \\
\hline 5 & $\mathrm{~F}$ & 16 & 2 & Right & $\mathrm{fpt}$ & 69 & 48 & - \\
\hline 6 & M & 30 & 2 & Left & fpt & 42 & 31 & - \\
\hline 7 & M & 12 & 2 & Right & $\mathrm{p}$ & 95 & 58 & - \\
\hline 8 & $\mathrm{~F}$ & 16 & 2 & Left & $\mathrm{fpt}$ & 75 & 60 & 55 \\
\hline 9 & $\mathrm{M}$ & 12 & 2 & Left & fp & 82 & 66 & 59 \\
\hline 10 & $\mathrm{M}$ & 12 & 2 & Right & $\mathrm{fp}$ & 88 & 72 & 87 \\
\hline \multirow[t]{2}{*}{ Mean/SD } & - & $16 / 6$ & $1.8 / 0.4$ & - & - & $76 / 15$ & $54 / 12$ & $67 / 17$ \\
\hline & & & & & & \multicolumn{3}{|c|}{ RMT (\% SO) } \\
\hline Controls & Sex & Age & & Dominant hand & & Nondominant & Dominant & \\
\hline $\mathrm{a}$ & $\mathrm{F}$ & 11 & n.a. & Right & n.a. & 46 & 43 & - \\
\hline $\mathrm{b}$ & $\mathrm{M}$ & 10 & n.a. & Right & n.a. & 52 & 58 & - \\
\hline $\mathrm{c}$ & $\mathrm{F}$ & 16 & n.a. & Right & n.a. & 49 & 49 & - \\
\hline $\mathrm{d}$ & $\mathrm{M}$ & 11 & n.a. & Right & n.a. & 57 & 60 & - \\
\hline e & $\mathrm{F}$ & 15 & n.a. & Right & n.a. & 43 & 51 & - \\
\hline $\mathrm{f}$ & $\mathrm{F}$ & 19 & n.a. & Right & n.a. & 36 & 39 & - \\
\hline $\mathrm{g}$ & $\mathrm{F}$ & 19 & n.a. & Right & n.a. & 29 & 35 & - \\
\hline $\mathrm{h}$ & $\mathrm{F}$ & 31 & n.a. & Right & n.a. & 34 & 29 & - \\
\hline Mean/SD & - & $17 / 7$ & - & - & - & $43 / 10$ & $46 / 11$ & - \\
\hline
\end{tabular}

RMT over affected and contralesional hemisphere. Patients' affected hemisphere shows a significantly heightened RMT.

F, female; M, male; MACS, Manual Ability Classification System (25); f, frontal; p, parietal; t, temporal; n.a., not applicable.

receiving therapy with intramuscular administration of botulinum toxin within 3 months before the investigation, or had metal implants, cardiac pacemakers, or mental retardation were not eligible to participate.

Patients included met the criteria of unilateral spastic cerebral palsy caused by unilateral prenatal or perinatal stroke with cortico-subcortical lesions in the middle cerebral artery territory. This had been verified by structural MRI before the study. Single-pulse, focal TMS applied separately over the affected and contralesional hemisphere revealed fast-conducting corticospinal pathways from the affected hemisphere to the paretic hand. In three subjects, TMS revealed an additional ipsilateral corticospinal pathway from the contralesional hemisphere to the paretic hand. In the analysis, only MEPs transmitted by way of preserved crossed corticospinal projections were included. Subjects' manual performance during daily life activities was classified as between level I ("handles objects easily and successfully") and level III ("handles objects with difficulty, needs help to prepare and/or modify activities"), according to the Manual Ability Classification System (25). A further inclusion criterion was a significant motor impairment of the paretic hand, with, however, at least a rudimentary preserved active grasp function. Mental status allowed patients to meet the requirements of the TMS investigation protocol.
Recruited patients' characteristics and the localization of the lesion are summarized in Table 1. Coronal slices of each patient's structural MRI are shown in Figure 1. Patients 2, 4, 5, and 6 had already participated in a previous study (11).

For comparison, an age-matched control group of healthy volunteers (2 female, range 10-31 y, median $15.5 \mathrm{y}$ ) was investigated. Their handedness was assessed by the Oldfield Handedness Inventory (26). Exclusion criteria for the subjects of the control group were the same as for the patients.

TMS was performed using either a MagStim 200 Stimulator combined with a BiStim module (Magstim, Withland, Wales, UK) or a Medtronic MagPro $\times 100$ Stimulator (Medtronic Functional Diagnostics, Minneapolis, $\mathrm{MN}$ ), both connected to a figure-of-eight-shaped coil (outer diameter of each loop $9 \mathrm{~cm}$ ). TMS was applied over the primary motor cortex with the coil placed tangentially to the scalp and the handle pointing backward and rotated away from the midline not more than $45^{\circ}$. This assures an induced current in the brain directed from posterior to anterior, which is optimal to activate the corticospinal system transsynaptically. Electromyography (EMG) was recorded bilaterally from the flexor pollicis brevis muscle (FPB) with a Toennies universal amplifier (Jäger Tonnies, Höchberg, Germany) or a D360

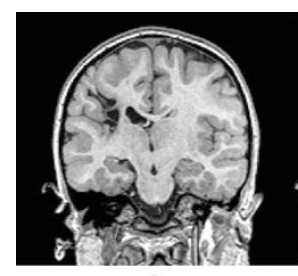

1

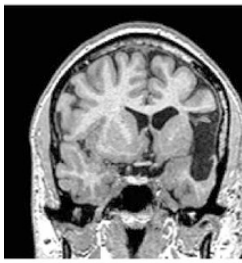

6

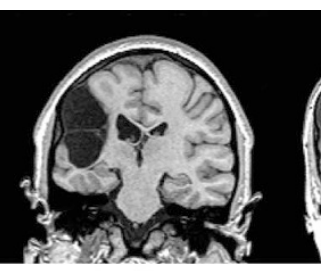

2

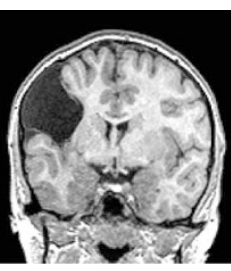

3

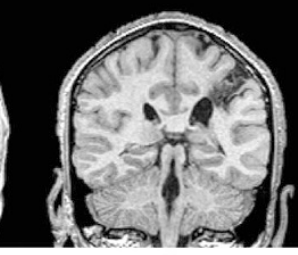

4

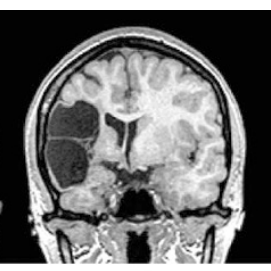

5

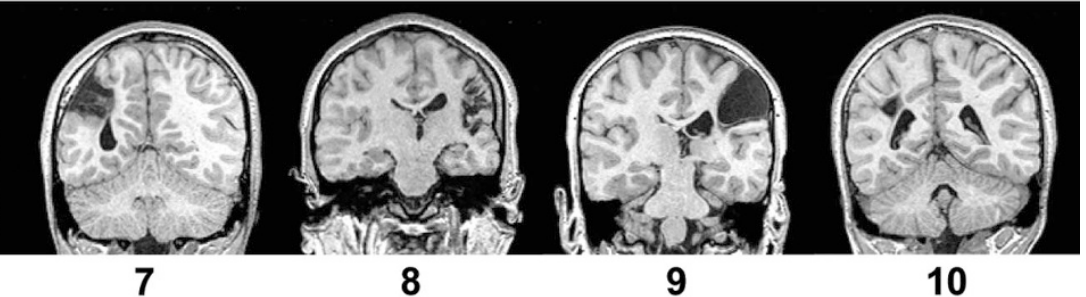

Figure 1. Coronal reconstructions from T1-weighted three-dimensional MRI from all patients grouped into patients with unilateral (1-7) and bilateral $(8-10)$ corticospinal tract to the paretic hand. 
amplifier (Digitimer, Ltd., Hertfordshire, UK) using self-adhesive surface electrodes in belly tendon montage. EMG signals were collected through CED 1401 laboratory interfaces (Cambridge Electronic Design, Cambridge, UK) with $5 \mathrm{kHz}$ sampling and fed to personal computers. Analysis was performed offline with CED Signal 2 Software.

Patients' affected (M1-aff) and contralesional hemispheres (M1-cl) as well as dominant (M1-dom) and nondominant hemispheres (M1-ndom) of controls were examined separately starting with a systematic search for the optimal position of the coil to elicit an MEP in the resting muscle. The coil was located according to anatomical landmarks, and stimulator output was increased in $10 \%$ increments until every trial produced an MEP greater than 100 $\mu \mathrm{V}$. In considering structural and anatomical alterations, the coil position was then adjusted to the optimal site ("hot spot") where the maximal MEP amplitude could be evoked. This site was marked on the scalp to ensure correct positioning of the coil throughout the experiment. Thereafter, the stimulator output was reduced in $1 \%$ increments to obtain resting motor threshold (RMT) of the relaxed FPB. RMT was defined as the percentage of stimulator output necessary to obtain an MEP response greater than $50 \mu \mathrm{V}$ in five of 10 consecutive trials in the relaxed muscle (27).

To measure short interval intracortical inhibition (SICI) and intracortical facilitation (ICF), the paired conditioning and test stimulus (TS) technique described by Kujirai et al. (16) was performed on the previously defined scalp positions of each hemisphere. The experiment consists of a subthreshold conditioning stimulus (CS) followed by a suprathreshold TS after variable interstimulus intervals (ISI). In healthy adult subjects, the test response is typically decreased at ISI of 2 to $4 \mathrm{~ms}$ (SICI). The most likely explanation for SICI is the activation of gamma-aminobutyric acid (GABA)ergic interneurons with inhibitory effect (18). With ISI longer than $6 \mathrm{~ms}$, facilitation of the test response occurs (ICF). ICF is thought to be mediated by glutamatergic interneurons with excitatory effects $(16,28)$. The subthreshold CS does not elicit a motor response in the target muscle nor does it produce changes on a subcortical level or change the excitability of motoneurons at the spinal cord level $(16,17,29)$. Any effect on the size of the response to the subsequent TS can therefore be interpreted as of intracortical origin $(30,31)$. In our experiments, the CS was set to $80 \%$ of the RMT. The intensity of the TS was set to $120 \%$ of RMT. To account for intertrial variability, we performed 10 trials with either unconditioned or conditioned TS with ISI of 2, 2.5, 3, 4, 5, 10, and $20 \mathrm{~ms}$ randomly intermixed, resulting in 80 stimuli in total. The time between trials was set to $3 \mathrm{~s}$.

Relaxation of the target muscle was monitored throughout the experiment. EMG activity was monitored continuously through visual feedback and recorded $100 \mathrm{~ms}$ before the magnetic stimulus. Trials with activation of the target muscle pre- or poststimulus were rejected offline because even minimal contraction of the muscle significantly reduces both intracortical inhibition and ICF (32).

Statistical analysis. Linear models were fitted to the RMT and to the logarithmically transformed SICI and ICF amplitudes. Only significant terms were included into the model. Random effects were added to account for the repeated measures per subject (33). This allows us to estimate the variability of the measurements of each patient and to compare this with the estimates and the variability of the residuals. The analysis was carried out by means of the MIXED procedure (SAS Institute, Cary, NC).

Results for SICI and ICF were calculated separately because there is evidence that they are caused by separate mechanisms (17). Results for M1-aff and M1-cl and M1-ndom are reported with reference to the M1-dom. The dominant hemisphere was chosen because the magnitude of SICI was reported to be slightly less in the dominant hemisphere compared with the nondominant hemisphere of healthy adults (34). Subsidiary pair-wise analysis between hemispheres was carried out ( $\mathrm{F}$ test, Wald test).

\section{RESULTS}

TMS was well tolerated, and none of the examined patients or controls reported any side effects during or after the investigation. In patients 7 and 10, RMT of the affected hemisphere was $95 \%$ and $88 \%$, respectively. Therefore, a TS of $120 \%$ RMT could not be obtained, and data had to be excluded from statistical analysis. The remaining eight patients had a median age of 16 (range 11-30) y. The control group consisted of eight subjects with a median age of 15.5 (range 10-31) y.

RMT. Compared with the M1-dom of controls, the RMT of M1-aff was significantly elevated by an amount of $0.26[95 \%$ confidence interval (CI) 0.13-0.39]. In contrast, no such difference in RMT was found for both the M1-cl and the M1-ndom (Table 1). Subsidiary pair-wise comparison by Wald test revealed a significantly elevated RMT of M1-aff compared with M1-cl and M1-ndom, respectively $(p<$ 0.0001). The difference in RMT between M1-cl versus M1ndom was not significant $(p=0.1543)$. RMT for single subjects are listed in Table 1.

SICI amplitudes. Compared with the M1-dom, the SICI amplitudes of M1-aff were significantly heightened by a factor of 2.38 [95\% CI, 1.75-3.23; $\log$ (SICI) 0.87 (95\% CI, 0.561.17)] (Fig. 2 and Table 2). SICI amplitudes of the nondominant hemisphere were significantly heightened by a factor of 1.59 [95\% CI, 1.44-1.76; log (SICI) 0.47 (95\% CI, $0.37-$ 0.57)]. Pair-wise analysis revealed significantly higher SICI amplitudes for M1-aff compared with M1-ndom (F test, $p=$ 0.0107). Figure 3 shows an example of conditioned MEP elicited over affected and contralesional hemispheres in a single subject (patient 1).

Effect of ISI on SICI amplitude. ISI had a significant effect on SICI amplitude. With every ISI increment of $1 \mathrm{~ms}$, SICI amplitudes increased by a factor of 1.29 [95\% CI, 1.18-1.41; $\log$ (SICI) 0.25 (95\% CI, 0.16-0.34)] (Fig. 2). This factor did not differ between hemispheres.

ICF amplitudes. Compared with the M1-dom, ICF amplitudes of M1-aff and M1-cl showed no significant difference, whereas the M1-ndom showed heightened ICF amplitudes by a factor of 1.41 [95\% CI, 1.19-1.65; $\log$ (ICF) 0.34 (95\% CI, $0.18-0.50)$ ] (Table 2).

Effect of ISI on ICF amplitude. ISI had no significant effect on ICF amplitude in general. There were interactions

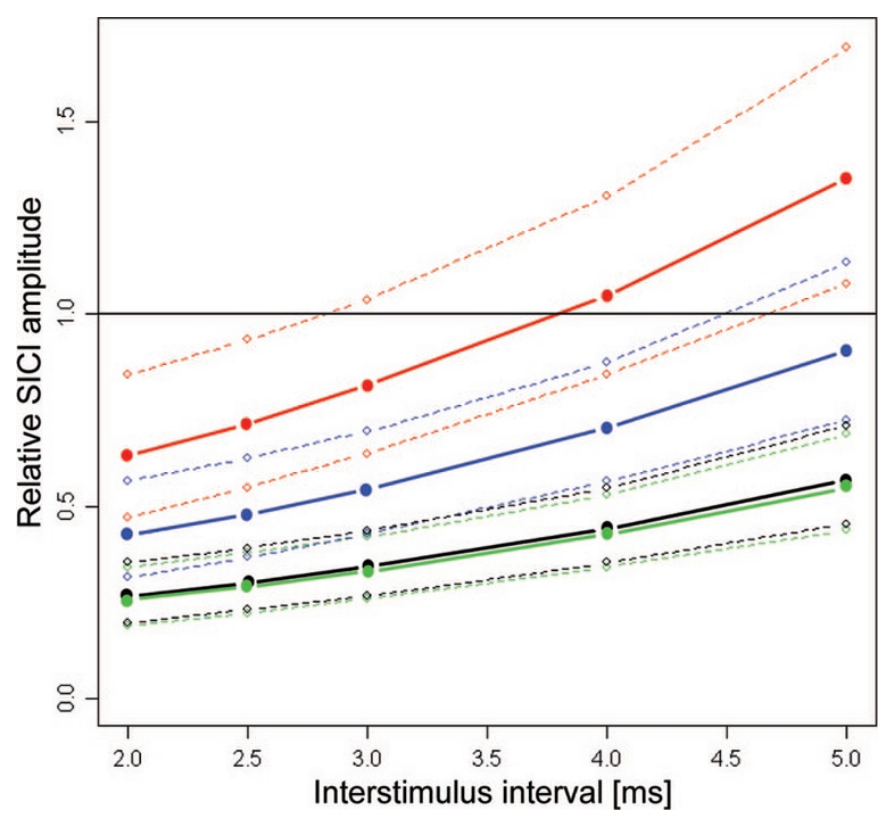

Figure 2. Relative SICI amplitudes. $y$ axis displays the estimated relative amplitude of the conditioned MEP as a ratio of the unconditioned MEP amplitude, plotted against ISI ( $x$ axis). Red, affected; green, contralesional hemisphere of patients; black, dominant; blue, nondominant hemisphere of controls. Dotted lines represent upper and lower 95\% CIs. M1-aff as well as M1-ndom show significantly heightened SICI amplitudes, with highest values for M1-aff. Additional pair-wise analysis (F test) between M1-aff and M1ndom reveal a significant difference. 
Table 2. Median SICI and ICF amplitudes for patients and controls

\begin{tabular}{cccccccccccccccccc}
\hline & \multicolumn{2}{c}{$2 \mathrm{~ms}$} & \multicolumn{2}{c}{$2.5 \mathrm{~ms}$} & \multicolumn{2}{c}{$3 \mathrm{~ms}$} & \multicolumn{2}{c}{$4 \mathrm{~ms}$} & \multicolumn{2}{c}{$5 \mathrm{~ms}$} & \multicolumn{2}{c}{$10 \mathrm{~ms}$} \\
\hline Patients $(n=8)$ & $\mathrm{cl}$ & aff & $\mathrm{cl}$ & aff & $\mathrm{cl}$ & aff & $\mathrm{cl}$ & aff & $\mathrm{cl}$ & aff & $\mathrm{cl}$ & aff & $\mathrm{cl}$ & aff \\
& 0.34 & 0.81 & 0.39 & 0.91 & 0.40 & 0.98 & 0.47 & 1.11 & 0.70 & 1.29 & 1.16 & 1.66 & 1.91 & 1.69 \\
Controls $(n=8)$ & $\mathrm{d}$ & nd & $\mathrm{d}$ & nd & $\mathrm{d}$ & nd & $\mathrm{d}$ & nd & $\mathrm{d}$ & nd & $\mathrm{d}$ & nd & $\mathrm{d}$ & nd \\
& 0.44 & 0.50 & 0.25 & 0.58 & 0.28 & 0.75 & 0.51 & 0.74 & 0.82 & 1.26 & 1.64 & 2.14 & 1.46 & 2.10 \\
\hline
\end{tabular}

For each ISI, the median SICI and ICF amplitudes, expressed as a percent ratio of the size of the unconditioned MEP, are given for the affected (aff) and contralesional (cl) hemispheres of patients and the dominant (d) and nondominant (nd) hemispheres of controls.

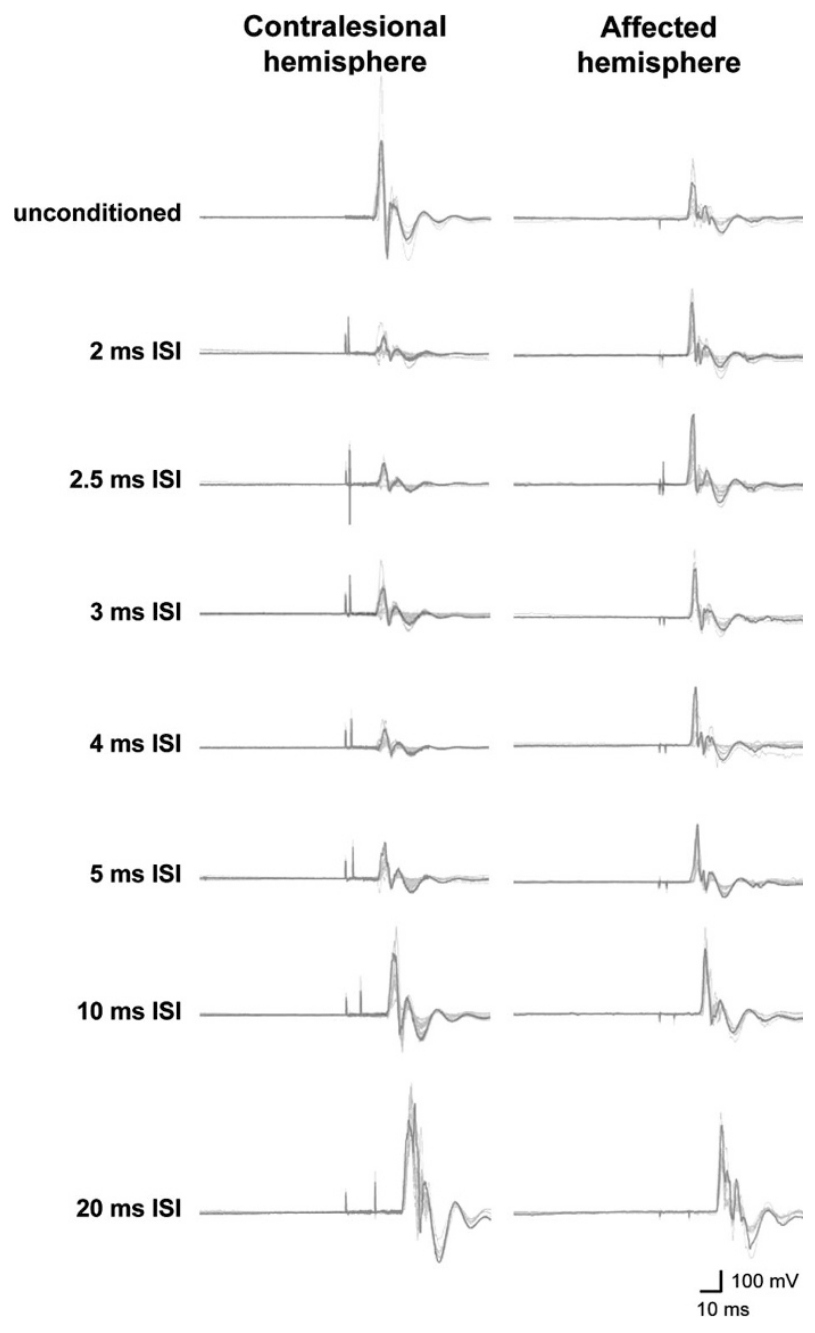

Figure 3. Exemplary SICI and ICF results of affected and contralesional hemispheres. In the contralesional hemisphere, the inhibitory and excitatory effect of a CS at short ISI (2-4 ms) and longer ISI (10, $20 \mathrm{~ms}$ ) on the TS are present. Over the affected hemisphere, the inhibitory effect of the CS at short ISI (SICI) is reduced.

between the ISI and the hemispheres, but these were not significant on the single hemisphere level. The estimates of the standard deviations of the random effects and the residuals are given in Table 3.

\section{DISCUSSION}

This study shows a significant reduction of SICI, indicating an increased intracortical excitability of the affected hemisphere in patients with congenital cortico-subcortical stroke. Corticospinal excitability was significantly reduced, as indicated by a heightened RMT. Although corticospinal excitabil-
Table 3. Single subject analysis of random effects

\begin{tabular}{lccccc}
\hline & \multicolumn{2}{c}{ SICI } & & \multicolumn{2}{c}{ ICF } \\
\cline { 2 - 3 } \cline { 5 - 6 } & Amplitude & ISI & & Amplitude & ISI \\
\hline SD of random effects & 0.48 & 0.15 & & 0.46 & 0.05 \\
SD of residuals & 0.75 & \multicolumn{3}{c}{0.55} \\
\hline
\end{tabular}

Single subject analysis was carried out to test for random effects. Table gives, separately for the logarithmically transformed SICI and ICF, standard deviation (SD) for amplitude and interstimulus interval as well as the SD of residuals.

ity is related to cell membrane excitability and therefore assumed to differ from mechanisms underlying SICI and ICF (35), changes in corticospinal as well as intracortical excitability can be interpreted as a direct consequence of the lesion.

The increase in motor threshold as reported for adult stroke patients $(36,37)$ is seen as a consequence of the structural damage of neurons. Reduction of SICI in the affected hemisphere as it has been shown in adult patients investigated in the postacute stage (12-15) as well as in chronic stage after stroke (38) might reflect a reduced number of GABAergic interneurons, which can be recruited due to the lesion. This is supported by the finding that SICI was eliminated in adults with stroke involving the motor cortex but not in patients with internal capsule, pontine, or striatocapsular lesions (15).

Reduced SICI could reflect a compensation for a lesion rather than the lesion itself. SICI in M1-aff was reduced but not eliminated, and susceptibility to the effect of different inhibitory ISI was sustained. A possible explanation for the observed shift of intracortical excitability could be a downregulation of GABA receptors, as shown in animals after cerebral ischemia (39-41). Alternatively to reduced GABAergic inhibition, increased activity of neuronal circuits responsible for excitatory effects at short ISI, as reported by Bütefisch et al. (42), could explain changes in intracortical excitability. Both explanations are compatible with the observation that SICI is also reduced in patients with cortical lesions not affecting the primary motor cortex (38). Because reduced SICI enhances plasticity and the capacity for motor learning (43), disinhibition could be interpreted as a prerequisite for use-dependent plasticity within the affected hemisphere. Alternatively, or in addition, reduced SICI may compensate for the lesion-induced reduction of cortical excitatory potentials, maintaining an appropriate corticospinal output to the paretic hand.

SICI of M1-cl was comparable with that of the dominant hemisphere of age-matched healthy controls. We assume from our data a normal excitability of the contralesional hemisphere in the chronic phase after congenital stroke, irrespective of 
temporarily changes, which might have happened at earlier stages of recovery, as described in adulthood stroke $(14,44,45)$.

ICF of the affected hemisphere showed no difference with the M1-dom. This result is consistent with reports for adulthood stroke $(13,14,42,44)$ and might be explained by the different mechanisms responsible for the inhibitory and facilitating effect of the CS. In conclusion, despite differences in the maturational state of the motor system at the time point when the lesion occurred, the results of this study do not appear to reflect any differences in the adaptive properties after congenital versus adulthood stroke (46).

\section{REFERENCES}

1. Celnik PA, Cohen LG 2004 Modulation of motor function and cortical plasticity in health and disease. Restor Neurol Neurosci 22:261-268

2. Hallett M 2001 Plasticity of the human motor cortex and recovery from stroke. Brain Res Brain Res Rev 36:169-174

3. Pascual-Leone A, Amedi A, Fregni F, Merabet LB 2005 The plastic human brain cortex. Annu Rev Neurosci 28:377-401

4. Krageloh-Mann I 2004 Imaging of early brain injury and cortical plasticity. Exp Neurol 190:S84-S90

5. Maegaki Y, Maeoka Y, Ishii S, Shiota M, Takeuchi A, Yoshino K, Takeshita K 1997 Mechanisms of central motor reorganization in pediatric hemiplegic patients. Neuropediatrics 28:168-174

6. Eyre JA 2003 Development and plasticity of the corticospinal system in man. Neural Plast 10:93-106

7. Eyre JA, Taylor JP, Villagra F, Smith M, Miller S 2001 Evidence of activitydependent withdrawal of corticospinal projections during human development. Neurology 57:1543-1554

8. Farmer SF, Harrison LM, Ingram DA, Stephens JA 1991 Plasticity of central motor pathways in children with hemiplegic cerebral palsy. Neurology 41:1505-1510

9. Carr LJ, Harrison LM, Evans AL, Stephens JA 1993 Patterns of central motor reorganization in hemiplegic cerebral palsy. Brain 116:1223-1247

10. Staudt M, Grodd W, Gerloff C, Erb M, Stitz J, Krageloh-Mann I 2002 Two types of ipsilateral reorganization in congenital hemiparesis: a TMS and fMRI study. Brain 125:2222-2237

11. Staudt M, Gerloff C, Grodd W, Holthausen H, Niemann G, Krageloh-Mann I 2004 Reorganization in congenital hemiparesis acquired at different gestational ages. Ann Neurol 56:854-863

12. Liepert J, Storch P, Fritsch A, Weiller C 2000 Motor cortex disinhibition in cute stroke. Clin Neurophysiol 111:671-676

13. Cicinelli P, Pasqualetti P, Zaccagnini M, Traversa R, Oliveri M, Rossini PM 2003 Interhemispheric asymmetries of motor cortex excitability in the postacute stroke stage: a paired-pulse transcranial magnetic stimulation study. Stroke 34:2653-2658

14. Manganotti P, Patuzzo S, Cortese F, Palermo A, Smania N, Fiaschi A 2002 Motor disinhibition in affected and unaffected hemisphere in the early period of recovery after stroke. Clin Neurophysiol 113:936-943

15. Liepert J, Restemeyer C, Kucinski T, Zittel S, Weiller C 2005 Motor strokes: the lesion location determines motor excitability changes. Stroke 36:2648-2653

16. Kujirai T, Caramia MD, Rothwell JC, Day BL, Thompson PD, Ferbert A, Wroe S, Asselman P, Marsden CD 1993 Corticocortical inhibition in human motor cortex. J Physiol 471:501-519

17. Ziemann U 1999 Intracortical inhibition and facilitation in the conventional paired TMS paradigm. Electroencephalogr Clin Neurophysiol Suppl 51:127-136

18. Ilic TV, Meintzschel F, Cleff U, Ruge D, Kessler KR, Ziemann U 2002 Shortinterval paired-pulse inhibition and facilitation of human motor cortex: the dimension of stimulus intensity. J Physiol 545:153-167

19. Ilic TV, Ziemann U 2005 Exploring motor cortical plasticity using transcranial magnetic stimulation in humans. Ann NY Acad Sci 1048:175-184

20. Eyre JA, Miller S, Ramesh V 1991 Constancy of central conduction delays during development in man: investigation of motor and somatosensory pathways. J Physiol 434:441-452

21. Fietzek UM, Heinen F, Berweck S, Maute S, Hufschmidt A, Schulte-Monting J, Lucking CH, Korinthenberg R 2000 Development of the corticospinal system and hand motor function: central conduction times and motor performance tests. Dev Med Child Neurol 42:220-227

22. Mall V, Berweck S, Fietzek UM, Glocker FX, Oberhuber U, Walther M, Schessl J, Schulte-Monting J, Korinthenberg R, Heinen F 2004 Low level of intracortical inhibition in children shown by transcranial magnetic stimulation. Neuropediatrics 35:120-125

23. Garvey MA, Ziemann U, Bartko JJ, Denckla MB, Barker CA, Wassermann EM 2003 Cortical correlates of neuromotor development in healthy children. Clin Neurophysiol 114:1662-1670

24. Vexler ZS, Sharp FR, Feuerstein GZ, Ashwal S, Thoresen M, Yager JY, Ferriero DM 2006 Translational stroke research in the developing brain. Pediatr Neurol 34:459-463

25. Eliasson AC, Krumlinde-Sundholm L, Rosblad B, Beckung E, Arner M, Ohrvall AM, Rosenbaum P 2006 The Manual Ability Classification System (MACS) for children with cerebral palsy: scale development and evidence of validity and reliability. Dev Med Child Neurol 48:549-554

26. Oldfield RC 1971 The assessment and analysis of handedness: the Edinburgh inventory. Neuropsychologia 9:97-113

27. Rossini PM, Barker AT, Berardelli A, Caramia MD, Caruso G, Cracco RQ, Dimitrijević MR, Hallett M Katayama Y, Lücking CH 1994 Non-invasive electrical and magnetic stimulation of the brain, spinal cord and roots: basic principles and procedures for routine clinical application. Report of an IFCN committee. Electroencephalogr Clin Neurophysiol 91:79-92

28. Ziemann U, Lonnecker S, Steinhoff BJ, Paulus W 1996 Effects of antiepileptic drugs on motor cortex excitability in humans: a transcranial magnetic stimulation study. Ann Neurol 40:367-378

29. Ziemann U, Rothwell JC, Ridding MC 1996 Interaction between intracortical inhibition and facilitation in human motor cortex. J Physiol 496:873-881

30. Nakamura H, Kitagawa H, Kawaguchi Y, Tsuji H 1997 Intracortical facilitation and inhibition after transcranial magnetic stimulation in conscious humans. J Physiol 498:817-823

31. Di Lazzaro V, Restuccia D, Oliviero A, Profice P, Ferrara L, Insola A, Mazzone P, Tonali P, Rothwell JC 1998 Magnetic transcranial stimulation at intensities below active motor threshold activates intracortical inhibitory circuits. Exp Brain Res 119:265-268

32. Ridding MC, Taylor JL, Rothwell JC 1995 The effect of voluntary contraction on cortico-cortical inhibition in human motor cortex. J Physiol 487:541-548

33. Verbeke G, Molenberghs G. 1997 Linear Mixed Models in Practice: A SASOriented Approach. Springer, Berlin

34. Ilic TV, Jung P, Ziemann U 2004 Subtle hemispheric asymmetry of motor cortical inhibitory tone. Clin Neurophysiol 115:330-340

35. Chen R, Tam A, Butefisch C, Corwell B, Ziemann U, Rothwell JC, Cohen LG 1998 Intracortical inhibition and facilitation in different representations of the human motor cortex. J Neurophysiol 80:2870-2881

36. Byrnes ML, Thickbroom GW, Phillips BA, Mastaglia FL 2001 Long-term changes in motor cortical organisation after recovery from subcortical stroke. Brain Res 889:278-287

37. Pennisi G, Alagona G, Rapisarda G, Nicoletti F, Costanzo E, Ferri R, Malaguarnera M, Bella R 2002 Transcranial magnetic stimulation after pure motor stroke. Clin Neurophysiol 113:1536-1543

38. Liepert J, Hamzei F, Weiller C 2004 Lesion-induced and training-induced brain reorganization. Restor Neurol Neurosci 22:269-277

39. Hagemann G, Redecker C, Neumann-Haefelin T, Freund HJ, Witte OW 1998 Increased long-term potentiation in the surround of experimentally induced focal cortical infarction. Ann Neurol 44:255-258

40. Buchkremer-Ratzmann I, Witte OW 1997 Extended brain disinhibition following small photothrombotic lesions in rat frontal cortex. Neuroreport 8:519-522

41. Witte OW 1998 Lesion-induced plasticity as a potential mechanism for recovery and rehabilitative training. Curr Opin Neurol 11:655-662

42. Butefisch CM, Netz J, Wessling M, Seitz RJ, Homberg V 2003 Remote changes in cortical excitability after stroke. Brain 126:470-481

43. Ziemann U, Muellbacher W, Hallett M, Cohen LG 2001 Modulation of practicedependent plasticity in human motor cortex. Brain 124:1171-1181

44. Liepert J, Hamzei F, Weiller C 2000 Motor cortex disinhibition of the unaffected hemisphere after acute stroke. Muscle Nerve 23:1761-1763

45. Shimizu T, Hosaki A, Hino T, Sato M, Komori T, Hirai S, Rossini PM 2002 Motor cortical disinhibition in the unaffected hemisphere after unilateral cortical stroke. Brain 125:1896-1907

46. Mosch SC, Max JE, Tranel D 2005 A matched lesion analysis of childhood versus adult-onset brain injury due to unilateral stroke: another perspective on neural plasticity and recovery of social functioning. Cogn Behav Neurol 18:5-17 